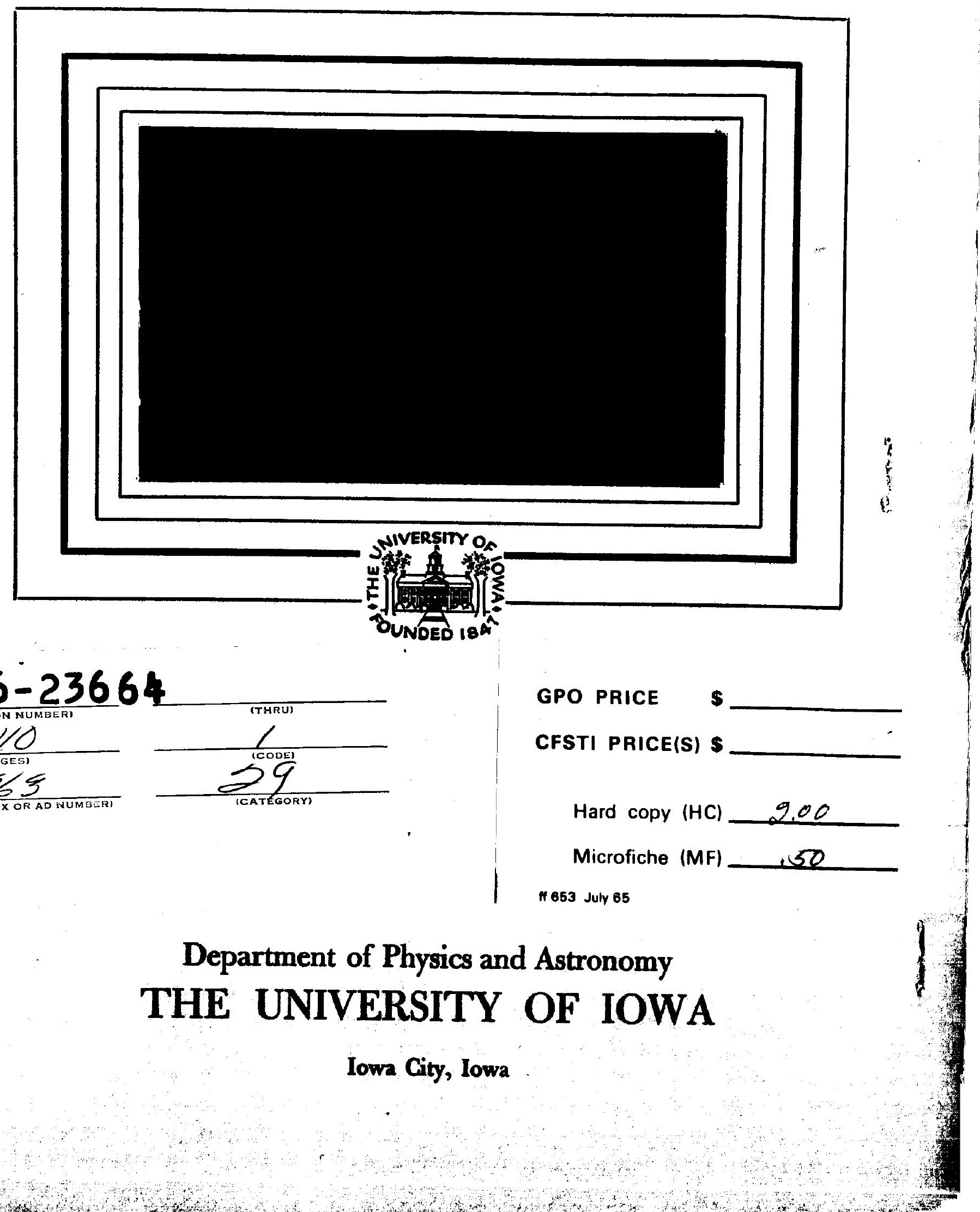




\section{EXPLORER 12 OBSERVATIONS OF THE TEMPORAL VARIATIONS OF LOW-ENERGY \\ ELECTRON INTENSITIES IN THE \\ OUTER RADIATION ZONE \\ DURING GEOMAGNETIC STORMS*}

by

L. A. Frank

\section{Department of Physics and Astronomy University of Iowa Iowa City, Iowa}

March 1966

*Research supported in part by the National Aeronautics and Space Administration under Grant NsG-233-62 and by the Office of Naval Research under Contract Nonr-1509(06). 
Abstract

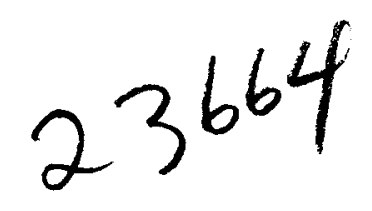

Large increases of electron $100 \mathrm{eV} \lesssim \mathrm{E}_{\mathrm{e}} \lesssim 40 \mathrm{keV}$ energy fluxes over $L \simeq 2.8$ to $L \simeq 4.0$ were observed at the onset of magnetic storms on 1 October and 29 October 1961 with instrumentation on Explorer 12. The omnidirectional energy fluxes at $\mathrm{L}=3.5$ were $\sim 1000 \mathrm{ergs}\left(\mathrm{cm}^{2}-\mathrm{sec}\right)^{-1}$ for these two events, the duration of these events was approximately one day and the peak energy flux was positioned at $\mathrm{L} \simeq 3.0$. The large enhancement of electron $100 \mathrm{eV} \lesssim \mathrm{E}_{\mathrm{e}} \lesssim 40 \mathrm{keV}$ energy fluxes on 1 October is coincident with large decreases of electron $\mathrm{E}_{\mathrm{e}} \gtrsim 1.6 \mathrm{MeV}$ intensities and with increases of electron $40 \mathrm{keV} \leq \mathrm{E}_{\mathrm{e}} \leq 100 \mathrm{keV}$ intensities in the outer radiation zone. Although no spectral information concerning the electron $100 \mathrm{eV} \lesssim \mathrm{E}_{\mathrm{e}} \lesssim 40 \mathrm{keV}$ fluxes is available, estimates of the decrease of the magnetic field on the surface of the earth at the magnetic equator for monoenergetic electron intensities corresponding to the observed energy fluxes are $\sim 120 \gamma$ for $\mathrm{E}_{\mathrm{e}}=100 \mathrm{eV}, \sim 60 \gamma$ for $\mathrm{E}_{\mathrm{e}}=500 \mathrm{eV}$ and $\sim 30 \gamma$ for $\mathrm{E}_{\mathrm{e}}=2 \mathrm{keV}$ during the main phase of the magnetic storm. The observations reported here strongly suggest that these electrons form a ring 
current centered at $\sim 3 \mathrm{R}_{\mathrm{E}}$ which is responsible for a substantial fraction of the main phase and the rapid-decay component DRI of magnetic storms.<smiles>[AlH2]</smiles> 


\section{Introduction}

Observations of electron intensities near the geomagnetic equator in the outer radiation zone have been obtained with satellite instrumentation over a broad range of electron energies extending from $\sim 1 \mathrm{eV}$ to $\sim 10 \mathrm{MeV}$. The temporal variations and radial profiles of intensities of electrons at the geomagnetic equator in the outer radiation zone are dependent upon the energy of the electrons under observation. For example, a comparison of observations of electron $\mathrm{E}_{\mathrm{e}} \sim 50 \mathrm{keV}$ and $\mathrm{E}_{\mathrm{e}} \sim 1 \mathrm{MeV}$ intensities in the outer radiation zone reveals (1) the radial dependence of electron $\mathrm{E}_{\mathrm{e}} \sim 50 \mathrm{keV}$ intensities is typically by a factor of $\lesssim 10$ over the radial distance 3 to $8 \mathrm{R}_{\mathrm{E}}\left(\mathrm{R}_{\mathrm{E}}=\right.$ earth radius) [cf. Frank, Van Allen, Whelpley and Craven, 1963; Freeman, 1964] whereas the corresponding variation of electron $\mathrm{E}_{\mathrm{e}} \sim 1 \mathrm{MeV}$ intensities is typically by a factor $\sim 10^{3}-10^{4}$ with a peak of intensities at $L \sim 4$, and (2) during the onset of geomagnetic activity the electron $\mathrm{E}_{\mathrm{e}} \sim 50 \mathrm{keV}$ intensities are observed to increase by a factor $10-100$ coincident with a decrease of electron $\mathrm{E}_{\mathrm{e}} \sim 1 \mathrm{MeV}$ intensities by a factor $\sim 10-100$ within the temporal resolution of the 
measurements ( I day) [cf. Freeman, 1964; Frank, Van Allen and Hills, 1964]. Of specific interest in this present . study are observations of the temporal variations of the energy flux of electrons $100 \mathrm{eV} \lesssim \mathrm{E}_{\mathrm{e}} \lesssim 40 \mathrm{keV}$ during periods of geomagnetic activity with instrumentation utilizing cadmium sulfide crystals flown on Explorer 12 and comparison of these variations of energy flux with simultaneous observations of higher energy electron $\left(E_{e} \sim 50 \mathrm{keV}\right.$ and $\left.E_{e} \sim 1 \mathrm{MeV}\right)$ intensities. These observations contribute further to the growing body of information concerning outer radiation zone electrons which should eventually delineate the principal source and loss mechanisms for electrons in this region. 
II. Instrumentation

Explorer 12 was launched on 16 August 1961 into an orbit with initial apogee $83,600 \mathrm{~km}$ and perigee $6,700 \mathrm{~km}$ geocentric radial distances, inclination $33^{\circ}$ and period 26.5 hours. Transmission of data extended from launch to 6 December 1961. At launch the line of apsides of the spacecraft orbit was within $\sim 5^{\circ}$ of the solar direction as viewed from the center of the earth; hence the ranges of local times of the spacecraft position in the outer radiation zone $(L \sim 4)$ were approximately $\sim 7: 00$ to $1: 00$ and $14: 00$ to 8:00 for outbound and inbound passes, respectively, over the period of data reception.

The University of Iowa complement of detectors included a shielded $\left(\sim 1 \mathrm{gm}(\mathrm{cm})^{-2}\right)$ Anton type 302 G.M. tube, a magnetic spectrometer utilizing three thin-windowed (1.2 $\mathrm{mg}(\mathrm{cm})^{-2}$ mica) Anton type 213 G.M. tubes, and three cadmium sulfide crystals for measurements of the total energy flux of protons $E_{p} \gtrsim I \mathrm{keV}$ and electrons $E_{e} \gtrsim 200 \mathrm{eV}$. A summary of the characteristics of these various detectors is given in Table I. A more complete description has been given previously by Freeman [1964]. 
6

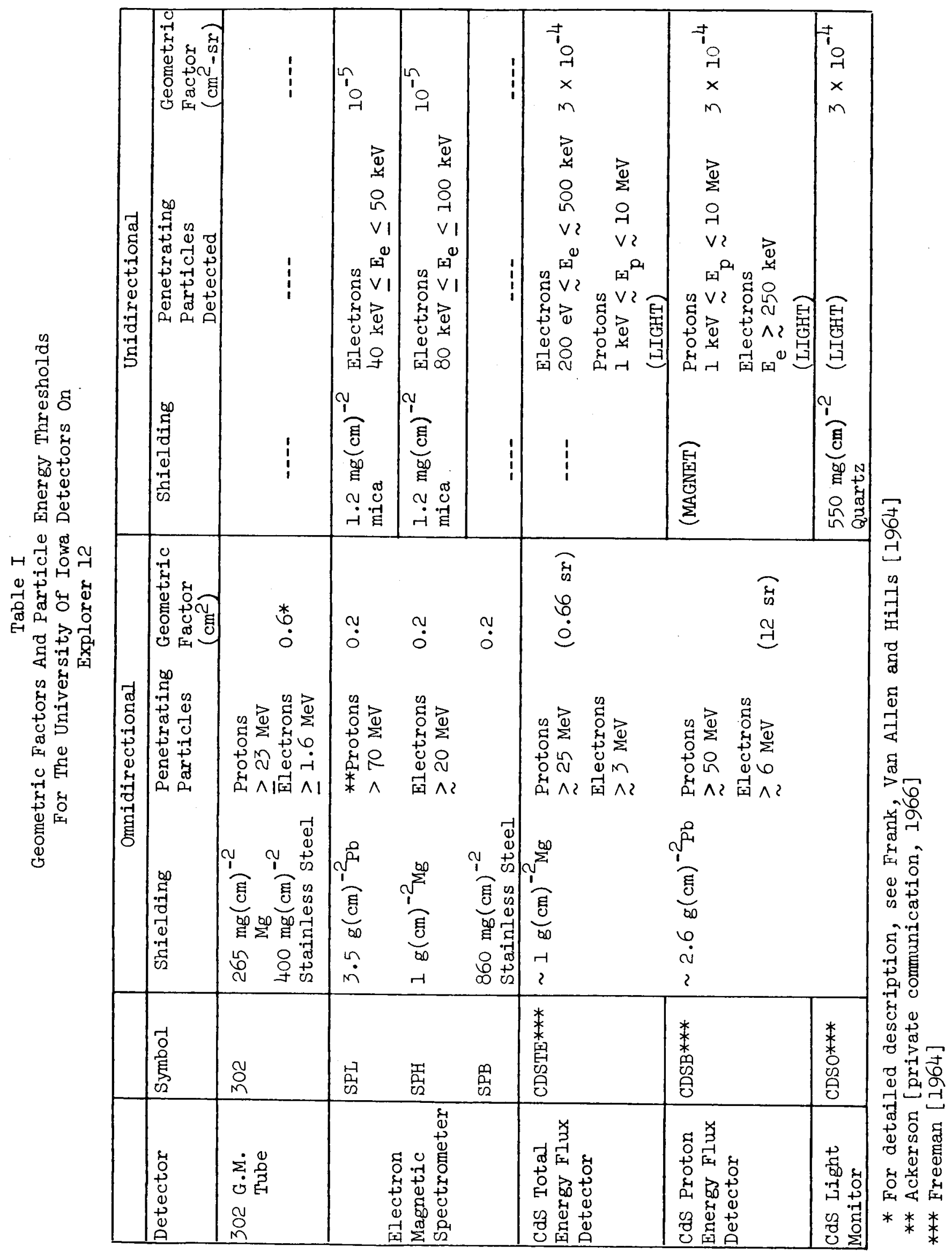


The response of each detector was accumulated for 10.24 seconds by the on-board experiment encoder and the contents of the accumulators redundantly telemetered at the end of each sampling interval. The encoder accumulators were time-shared such that each detector response was sampled once every 79 seconds.

Of particular interest in this present study are the responses of the cadmium sulfide crystals in the outer radiation zone. Pertinent characteristics of these three detectors [Freeman, 1964] are

1) CDSTE (cadmium sulfide total energy detector) is an unshielded cadmium sulfide crystal with a collimated field of view of $10^{-2}$ steradian which has a response proportional to the total energy flux of protons $E_{p} \gtrsim I \mathrm{keV}$ and $E_{e} \gtrsim 200 \mathrm{eV}$. The efficiency of this detector for particles of these energies is $\sim 0.2$ count- $\mathrm{cm}^{2}-\mathrm{sr}(\mathrm{erg})^{-1}$ and decreases with decreasing charged particle energies below $\mathrm{E}_{\mathrm{p}} \sim 1 \mathrm{keV}$ and $\mathrm{E}_{\mathrm{e}} \sim 200 \mathrm{eV}$. Throughout the present discussion the maximum efficiency as quoted above will be assumed. The efficiency of CdS crystals has been shown to be nearly the same for electrons, protons, alpha particles and x-rays [Freeman, 1961]. 
The minimum detectable energy flux for CDSTE is

$\sim 1 \operatorname{erg}\left(\mathrm{cm}^{2}-\sec -\mathrm{sr}\right)^{-1}$.

2) CDSB (cadmium sulfide detector with broom magnet)

is an unshielded cadmium sulfide crystal identical

to CDSTE with the exception of a "broom" magnet

positioned in the collimator to prohibit electrons

$\mathrm{E}_{\mathrm{e}} \lesssim 250 \mathrm{keV}$ from reaching the crystal. The

efficiency of this crystal is within a factor of

approximately two that of the CDSTE discussed

above. Protons $E_{p} \gtrsim 400 \mathrm{eV}$ are able to reach the

crystal and hence CDSB can be used to distinquish

the response of CDSTE as being attributable to

electrons $\mathrm{E}_{\mathrm{e}} \lesssim 250 \mathrm{keV}$ and protons $\mathrm{E}_{\mathrm{p}} \approx 400 \mathrm{eV}$ or

electrons $E_{e} \gtrsim 250 \mathrm{keV}$ and protons $E_{p} \gtrsim 400 \mathrm{eV}$.

3) CDSO (cadmium sulfide optical monitor) is a cadmium sulfide crystal equipped with a collimator identical

to CDSTE and CDSB but with a quartz window as

shielding to monitor the background response of

the detectors to light and $\mathrm{x}$-rays.

All unidirectional detectors were mounted on the space-

craft such that the axes of their fields-of-view were perpendicular to the spacecraft spin axis. Since the spin period of Explorer 12 was $\sim 2$ seconds and the accumulation interval was 10.24 seconds, 
the telemetered response of the detectors is essentially a spin-average over several spacecraft rotations with the responses of all unidirectional detectors averaged over a common circle of directions on the celestial sphere. The spin axis of Explorer 12 was directed toward right ascension $47^{\circ}$ and declination $-27.5^{\circ}$ at launch. In the outer radiation zone the detectors were averaging predominantly over trapped particle pitch angles (the half-angle of the dumping cone at $L=5$ is $\sim 5^{\circ}$ ). 


\section{Observations}

A summary of the responses of CDSTE, CDSB and CDSO is displayed in Figure 1 for the period 21 September through 14 October 1961 for $\mathrm{L}=2.5,3.0,3.5$, and 4.0. The temporal resolution of the measurements is determined by the orbital period ( I day); observations during several orbits during this period are missing due to lack of reception of the satellite telemetry signal. For $\mathrm{L}=3.0$ and 3.5 the CDSTE response shows strong enhancements of energy flux on 1 October 1961 which are unique with respect to the smoothly varying profiles before and after this date. On the adjacent L-shells, $\mathrm{L}=2.5$ and 4.0 , only a relatively small increase occurs during the period 1-2 October 1961. Inspection of the response of the optical monitor, CDSO, reveals that its response remained at background levels throughout the period, thus eliminating light and $\mathrm{x}$-rays as predominant contributors to the CDSTE response. The dark-current responses (counting rate near apogee, no light contamination) of CDSTE, CDSB and CDSO are $1.9,1.1$ and 0.2 counts $(\mathrm{sec})^{-1}$, respectively, for this period of observations. Further, at $L=3.0$, the increase of the response of CDSTE on 1 October was by a factor of $\sim 5$ over the response during the preceding orbit on 30 september 
whereas the increase of the response of CDSB (with broom magnet) was $\lesssim 50 \%$ for the same orbits. These observational evidences show that the response of CDSTE on 1 october is predominantly attributable to electrons $\mathrm{E}_{\mathrm{e}} \lesssim 250 \mathrm{keV}$ or protons $\mathrm{E}_{\mathrm{p}} \approx 400 \mathrm{eV}$. The corresponding peak energy fluxes, spin-averaged by the rotation of the spacecraft and assuming maximum efficiency of the detector (i.e., a lower limit to the energy flux), observed on 1 October 1961 are $\sim 125$

$\operatorname{ergs}\left(\mathrm{cm}^{2}-\mathrm{sec}-\mathrm{sr}\right)^{-1}$ and $100 \mathrm{ergs}\left(\mathrm{cm}^{2}-\mathrm{sec}-\mathrm{sr}\right)^{-1}$ at $\mathrm{L}=3.0$ and 3.5, respectively. Also shown in Figure 1 (top) is the daily variation in mean horizontal intensity at Guam. The enhancement of energy flux observed by CDSTE is coincident with the main phase of a large magnetic storm on 1 October 1961. A further similar observation of severe enhancement of energy fluxes during the main phase of a geomagnetic storm is displayed in Figure 2 for the period 21 October through 13 November 1961. On 29 October, an energy flux of $\sim 200 \mathrm{ergs}\left(\mathrm{cm}^{2}-\mathrm{sec}-\mathrm{sr}\right)^{-1}\left(\lambda_{\mathrm{m}}=-21^{\circ}\right)$ was observed coincident with a large decrease in the horizontal intensity of the earth's magnetic field observed at the surface of the earth near the magnetic equator. A similar event, although clouded by loss of telemetry, occurs during 7-8 November. 
Returning to Figure 1 , the large range of magnetic latitudes $\left(20^{\circ} \lesssim \lambda_{\mathrm{m}} \lesssim 45^{\circ}\right)$ of the observations necessitates an investigation of the latitude dependence of the responses of these detectors in order to ascertain that the enhancement of energy fluxes on 1 October 1961 is not a manfestation of differing magnetic latitudes of the observations. In Figure 3 all CDSTE responses shown in Figure 1 for $L=3.5$ are displayed as a function of the magnetic latitude of the observation. For the periods preceding and following 1 October, 21-30 September, and 2-14 October 1961 the CDSTE responses are smoothly increasing with decreasing geomagnetic latitude and indicate that the energy fluxes during the recovery phase are higher by a factor of $\sim 2$ compared with pre-storm fluxes over the latitude range $25^{\circ}-45^{\circ}$. The variations of intensities shown in Figure 1, excluding I October, can be accounted for by the latitude dependence of the observations for these two periods. Further reference to Figure 3 clearly shows that the enhancement of energy flux on 1 October is not a manifestation of the latitude dependence of the observations but is Indeed a large temporal variation of the electron energy fluxes. The same analysis applies to the data for $L=3.0$. Simultaneous measurements obtained with the G.M. tubes are displayed in Figure 4 for 
$L=3.5$. The 302 G.M. tube response decreases by a factor of $\sim 2$ at the onset of the geomagnetic storm coincident with the increase of low-energy electron energy fluxes observed by CDSTE. These rapid decreases of 302 G.M. response (predominantly attributable to temporal variations of the electron $\mathrm{E}_{\mathrm{e}} \gtrsim 1.6 \mathrm{MeV}$ intensities in the outer radiation zone) coincident with the onset of geomagnetic activity have been reported previously [cf. Freeman, 1964; Frank, Van Allen and Hills, 1964]. The responses of the magnetic spectrometer G.M. tubes, SpL and SpH, $\left(40 \mathrm{keV} \leq \mathrm{E}_{\mathrm{e}} \leq 50 \mathrm{keV}\right.$ and $80 \mathrm{keV}$ $\leq E_{e} \leq 100 \mathrm{keV}$, respectively) have also been included in Figure 4. The responses of these detectors show a sharp peak on 1 October. Unfortunately the background G.M. tube in the spectrometer failed previous to the period of present interest but its response usually decreases coincident with the decrease in the 302 G.M. tube response at the onset of geomagnetic activity [Freeman, 1964]. Solid upper limits on the intensities of electrons $40 \mathrm{keV} \leq \mathrm{E}_{\mathrm{e}} \leq 50 \mathrm{keV}$ and $80 \mathrm{keV} \leq \mathrm{E}_{\mathrm{e}} \leq 100 \mathrm{keV}$ are $2 \times 10^{7}\left(\mathrm{~cm}^{2}-\mathrm{sec}\right)^{-1}$ and $1.5 \times 10^{7}$ $\left(\mathrm{cm}^{2}-\mathrm{sec}\right)^{-1}$, respectively. Omnidirectional intensities $J_{0}$ are obtained from the observed spin-averaged unidirectional intensities $\bar{j}$ by the relationship $J_{0} \simeq 10 \bar{j}$ and are accurate to within a factor of 2 for a large range of pitch angle 
distributions $\left(\sin ^{n} \alpha\right)$ with arbitrary direction of the spin axis of the spacecraft with respect to the direction of the local magnetic field vector (See Frank, Van Allen and Hills [1964] for a similar analysis). Similarly the spin-averaged unidirectional energy fluxes corresponding to the CDSTE responses are multiplied by a factor of 10 to obtain omnidirectional energy fluxes. Hence an upper limit of the energy flux of electrons $40 \mathrm{keV} \leq \mathrm{E}_{e} \leq 100 \mathrm{keV}$ is $\sim 10$ ergs $\left(\mathrm{cm}^{2}-\mathrm{sec}\right)^{-1}$ compared with the simultaneous CDSTE observation of $\sim 1000$ ergs $\left(\mathrm{cm}^{2}-\mathrm{sec}\right)^{-1}$, electrons $\mathrm{E}_{\mathrm{e}} \lesssim 250 \mathrm{keV}$ or protons, $\mathrm{E}_{\mathrm{p}} \lesssim 400 \mathrm{eV}$. The relatively slow variations in $\mathrm{SpL}$ and $\mathrm{SpH}$ responses during the periods $21-30$ September and 2-14 October of Figure 4 are manifestations of a latitude dependence of the responses of these detectors as shown by a similar analyses as that given for CDSTE in Figure 3. Further restrictions on the energy range of the electrons contributing predominantly to the enhanced CDSTE response on 1 October are provided by the responses of the 302 G.M. tube on 30 November and 1 October shown in Figure 5. The responses of both the CDSTE and the 302 G.M. tube are displayed as a function of $I$ for the outbound pass preceding the storm (30 september) and the first outbound pass following the onset of the storm ( 1 October). The CDSTE response on 
1 October is substantially greater than pre-storm values from $L=2.8$ to 4.0 and is peaked at $L \simeq 3.0$ whereas the 302 G.M. response has catastrophically decreased beyond $L \simeq 4$ when compared to pre-storm values and shares a similar L-shell profile with CDSTE on 1 October. Assuming that the energy flux observed by CDSTE at $\mathrm{L}=3.0, \sim 1000$ $\operatorname{ergs}\left(\mathrm{cm}^{2}-\mathrm{sec}\right)^{-1}$, is due to monoenergetic electrons of energy $E_{e}$, the responses of the $302 \mathrm{G} . \mathrm{M}$. tube to nonpenetrating electrons $\left(\mathrm{E}_{\mathrm{e}} \lesssim 1.6 \mathrm{MeV}\right)$ of these intensities via the bremsstrahlung process have been calculated using the efficiency curve for a similarly shielded 302 G.M. tube given by Frank [1962] and are given in Table II. Comparison of the results of Table II with the observed 302 G.M. tube response of $\sim 10^{3}$ counts $(\mathrm{sec})^{-1}$ at $L=3.0$ eliminates electron $E_{e} \gtrsim 80 \mathrm{keV}$ energy fluxes as predominant contributions to the CDSTE response. Hence the SpL, SpH and 302 G.M. tube responses restrict the energy range of electrons observed by CDSTE to $\mathrm{E}_{\mathrm{e}} \lesssim 40 \mathrm{keV}$. On the other hand, if the electron spectrum observed with $\mathrm{SpL}$ and $\mathrm{SpH}$ (neglecting background corrections) is extrapolated to $\sim 300 \mathrm{keV}$, the response of the $302 \mathrm{G} \cdot \mathrm{M}$. tube on 1 October can be attributed to bremsstrahlung from electrons $50 \mathrm{keV} \lesssim \mathrm{E}_{\mathrm{e}} \lesssim 300 \mathrm{keV}$. In summary the enhanced energy fluxes observed at the onset of 
Table II

302 G.M. Tube Response Corresponding To Monoenergetic Electrons With

Energy Flux 1000 Ergs $\left(\mathrm{Cm}^{2}-\mathrm{Sec}\right)^{-1}$

\begin{tabular}{|c|c|c|c|}
\hline $\begin{array}{l}\text { Electron } \\
\text { Energy } \mathrm{E}_{\mathrm{e}}(\mathrm{keV})\end{array}$ & $\left(\mathrm{cm}^{2}-\mathrm{sec}\right)^{-1}$ & $\begin{array}{l}302 \text { Efficiency, } \epsilon \\
\text { Count-cm }{ }^{2} \text { (electron) }\end{array}$ & $\begin{array}{l}302 \text { counting Rate, } \\
\mathrm{R}, \text { counts }(\mathrm{sec})^{-1}\end{array}$ \\
\hline 15 & $4 \times 10^{10}$ & $2.5 \times 10^{-12}$ & 0.1 \\
\hline 20 & $3 \times 10^{10}$ & $2.5 \times 10^{-11}$ & 0.8 \\
\hline 30 & $2 \times 10^{10}$ & $7 \times 10^{-10}$ & 13 \\
\hline 40 & $1.5 \times 10^{10}$ & $10^{-8}$ & 150 \\
\hline 50 & $10^{10}$ & $4.5 \times 10^{-8}$ & 550 \\
\hline 80 & $8 \times 10^{9}$ & $5 \times 10^{-7}$ & $4 \times 10^{3}$ \\
\hline 125 & $5 \times 10^{9}$ & $2 \times 10^{-6}$ & $10^{4}$ \\
\hline 300 & $2 \times 10^{9}$ & $5 \times 10^{-6}$ & $10^{4}$ \\
\hline
\end{tabular}


geomagnetic storms with the $\operatorname{CDSTE}$ from $\mathrm{L} \simeq 2.8$ to $\simeq 4.0$

must be attributed to electrons $\mathrm{E}_{e} \approx 40 \mathrm{keV}$ or protons

$E_{p} \lesssim 400 \mathrm{eV}$ as delineated by the simultaneous responses

of companion detectors as noted above. 
Further evidence toward the identification of the particles predominantly contributing to the response of CDSTE on 1 october may be obtained by evaluating the energy densities of monoenergetic electrons and protons, separately, corresponding to the observed energy flux of $\sim 1000$ ergs $\left(\mathrm{cm}^{2}-\mathrm{sec}\right)^{-1}$. In Tables III (protons) and IV (electrons) are given the velocity $v$, energy density $\overline{\mathrm{E}}$ and omnidirectional intensity $J_{0}$ for protons and electrons of selected energies $\mathrm{E}$. The magnetic latitude of the observation on 1 October was $33^{\circ}$ at $I=3.5$; the corresponding magnetic field energy density, $B^{2} / 8 \pi$, is $2.1 \times 10^{-5} \mathrm{erg}(\mathrm{cm})^{-3}$. Also given in Tables III and IV are the ratios, $\beta$, of the charged particle energy density to the magnetic field energy density where

$$
\beta=\frac{\bar{E}}{\left(\frac{B^{2}}{8 \pi}\right)}
$$

is evaluated at $\mathrm{L}=3.5, \lambda_{\mathrm{m}}=33^{\circ}$. 
Table III

Intensities And Energy Densities of Monoenergetic Protons Corresponding To An Energy Flux of $1000 \operatorname{Ergs}\left(\mathrm{Cm}^{2}-\mathrm{SeC}\right)^{-1}$

\begin{tabular}{|c|c|c|c|c|}
\hline $\begin{array}{c}\text { Proton } \\
\text { Energy } \mathrm{E}_{\underline{p}}(\mathrm{keV})\end{array}$ & $\begin{array}{c}\text { Velocity } \\
\mathrm{cm}(\mathrm{sec})^{-1}\end{array}$ & $\begin{array}{c}\text { Proton } \\
\text { Engy Density } \\
\mathrm{ergs}(\mathrm{cm})^{-3}\end{array}$ & $\begin{array}{c}\text { Omnidirectional } \\
\text { Intensity Jo } \\
\left(\mathrm{cm}^{2}-\mathrm{sec}\right)^{-1}\end{array}$ & $\begin{array}{c}\beta=\frac{\overline{\mathrm{E}}}{\left(\frac{\mathrm{B}^{2}}{8 \pi}\right)} \\
\mathrm{B}=3.5, \lambda_{\mathrm{m}}=33^{\circ}\end{array}$ \\
\hline 0.1 & $1.4 \times 10^{7}$ & $7.2 \times 10^{-5}$ & $6 \times 10^{12}$ & 3.4 \\
0.2 & $2.0 \times 10^{7}$ & $5.1 \times 10^{-5}$ & $3 \times 10^{12}$ & 2.4 \\
0.5 & $3.1 \times 10^{7}$ & $3.2 \times 10^{-5}$ & $1.2 \times 10^{12}$ & 1.5 \\
\hline 1 & $4.4 \times 10^{7}$ & $2.3 \times 10^{-5}$ & $6 \times 10^{11}$ & 1.1 \\
2 & $6.2 \times 10^{7}$ & $1.6 \times 10^{-5}$ & $3 \times 10^{11}$ & 0.76 \\
5 & $9.8 \times 10^{7}$ & $10^{-5}$ & $1.2 \times 10^{11}$ & 0.48 \\
\hline 10 & $1.4 \times 10^{8}$ & $7.2 \times 10^{-6}$ & $6 \times 10^{10}$ & 0.34 \\
20 & $2.0 \times 10^{8}$ & $5.1 \times 10^{-6}$ & $3 \times 10^{10}$ & 0.24 \\
50 & $3.1 \times 10^{8}$ & $3.2 \times 10^{-6}$ & $1.2 \times 10^{10}$ & 0.15 \\
\hline 100 & $4.4 \times 10^{8}$ & $2.3 \times 10^{-6}$ & $6 \times 10^{9}$ & 0.11 \\
200 & $6.2 \times 10^{8}$ & $1.6 \times 10^{-6}$ & $3 \times 10^{9}$ & 0.08 \\
500 & $9.8 \times 10^{8}$ & $10^{-6}$ & $1.2 \times 10^{9}$ & 0.05 \\
\hline
\end{tabular}


Table IV

Intensities And Energy Densities

of Monoenergetic Electrons Corresponding

To An Energy Flux of 1000 Ergs $\left(\mathrm{Cm}^{2}-\mathrm{Sec}\right)^{-1}$

\begin{tabular}{|c|c|c|c|c|}
\hline $\begin{array}{c}\text { Electron } \\
\text { Energy } \mathrm{E}_{\mathrm{e}}(\mathrm{keV})\end{array}$ & $\begin{array}{l}\text { Velocity } \\
\mathrm{cm}(\mathrm{sec})^{-1}\end{array}$ & $\begin{array}{c}\text { Electron } \\
\text { Energy Density } \overline{\mathrm{E}} \\
\operatorname{ergs}(\mathrm{cm})^{-3}\end{array}$ & $\begin{array}{l}\text { Omnidirectional } \\
\text { Intensity } J_{o} \\
\left(\mathrm{~cm}^{2}-\mathrm{sec}\right)^{-1}\end{array}$ & $\begin{array}{c}B=\frac{\bar{E}}{\left(\frac{B^{2}}{8 \pi}\right)} \\
B: L=3.5, \lambda_{m}=33^{\circ}\end{array}$ \\
\hline $\begin{array}{l}0.1 \\
0.2 \\
0.5\end{array}$ & $\begin{array}{l}5.9 \times 10^{8} \\
8.4 \times 10^{8} \\
1.3 \times 10^{9}\end{array}$ & $\begin{array}{l}1.7 \times 10^{-6} \\
1.2 \times 10^{-6} \\
7.9 \times 10^{-7}\end{array}$ & $\begin{array}{l}6 \times 10^{12} \\
3 \times 10^{12} \\
1.2 \times 10^{12}\end{array}$ & $\begin{array}{l}8.1 \times 10^{-2} \\
5.7 \times 10^{-2} \\
3.8 \times 10^{-2}\end{array}$ \\
\hline $\begin{array}{l}1 \\
2 \\
5\end{array}$ & $\begin{array}{l}1.9 \times 10^{9} \\
2.7 \times 10^{9} \\
4.2 \times 10^{9}\end{array}$ & $\begin{array}{l}5.3 \times 10^{-7} \\
3.8 \times 10^{-7} \\
2.4 \times 10^{-7}\end{array}$ & $\begin{array}{l}6 \times 10^{11} \\
3 \times 10^{11} \\
1.2 \times 10^{11}\end{array}$ & $\begin{array}{l}2.5 \times 10^{-2} \\
1.8 \times 10^{-2} \\
1.1 \times 10^{-2}\end{array}$ \\
\hline $\begin{array}{l}10 \\
20 \\
50\end{array}$ & $\begin{array}{l}5.9 \times 10^{9} \\
8.2 \times 10^{9} \\
1.2 \times 10^{10}\end{array}$ & $\begin{array}{l}1.7 \times 10^{-7} \\
1.2 \times 10^{-7} \\
8.1 \times 10^{-8}\end{array}$ & $\begin{array}{l}6 \times 10^{10} \\
3 \times 10^{10} \\
1.2 \times 10^{10}\end{array}$ & $\begin{array}{l}8.1 \times 10^{-3} \\
5.7 \times 10^{-3} \\
3.9 \times 10^{-3}\end{array}$ \\
\hline
\end{tabular}


It is generally believed that $\beta \lesssim 0.1$ for the earth's magnetosphere [cf Dessler and Vestine, 1960; Van Allen, 1966]. Application of this restriction to the values of $\beta$ for protons given in Table III eliminates protons $\mathrm{E}_{\mathrm{p}} \lesssim 50 \mathrm{keV}$ as predominant contributors to the CDSTE response at $L=3.5$ on

1 October. Reference to Table IV shows that electrons $\mathrm{E}_{\mathrm{e}} \gtrsim 100 \mathrm{eV}$ survive this restriction. Hence the large enhancement of energy flux observed with the CDSTE on 1 October 1961 can be attributed to electrons $100 \mathrm{eV} \lesssim \mathrm{E}_{\mathrm{e}} \lesssim 40 \mathrm{keV}$. 
IV. Summary and Conclusions

Large increases of low-energy electron $100 \mathrm{eV} \lesssim \mathrm{E}_{\mathrm{e}} \lesssim 40 \mathrm{keV}$ energy fluxes coincident with the onset of two large geomagnetic storms during October 1961 over the L-shell range of $2.8 \lesssim \mathrm{L} \lesssim 4.0$ as observed with Explorer 12 have been presented. The observed electron energy fluxes at $L=3.5$ were $\sim 100 \mathrm{ergs}\left(\mathrm{cm}^{2}-\mathrm{sec}-\mathrm{sr}\right)^{-1}$ $\left(\lambda_{\mathrm{m}}=-33^{\circ}\right)$ on 1 October 1961 and $\sim 200 \operatorname{ergs}\left(\mathrm{cm}^{2}-\mathrm{sec}-\mathrm{sr}\right)^{-1}$ $\left(\lambda_{\mathrm{m}}=21^{\circ}\right)$ on 29 October 1961. The time duration of these enhancements is approximately 1 day. A detailed analysis of the 1 October event provides the following conclusions:

1) the peak in the energy flux profile as a function of $L$ occurs at $L \simeq 3.0$,

2) the maximum observed energy flux of electrons $100 \mathrm{eV} \lesssim \mathrm{E}_{\mathrm{e}} \lesssim 40 \mathrm{keV}$ is $\sim 1000 \operatorname{ergs}\left(\mathrm{cm}^{2}-\mathrm{sec}\right)^{-1}$ (accurate to within a factor of 2 ),

3) the 302 G.M. tube response (primarily due to penetrating electrons $\mathrm{E}_{\mathrm{e}} \gtrsim 1.6 \mathrm{MeV}$ ) catastrophically decreases at $I \sim 4.5$ by a factor $\sim 10^{2}$ coincident with the enhancement of low-energy electrons $100 \mathrm{eV} \lesssim \mathrm{E}_{\mathrm{e}} \approx 40 \mathrm{keV}$ at $\mathrm{L} \simeq 2.8$ to 4.0 , 
4) strong support of an increase of electron $40 \mathrm{keV} \leq \mathrm{E}_{\mathrm{e}} \leq 50 \mathrm{keV}$ and $80 \mathrm{keV} \leq \mathrm{E}_{\mathrm{e}} \leq 100 \mathrm{keV}$ intensities by a factor of $\sim 5$ at $\mathrm{L}=3.5$ on 1 October coincident with the enhancement of low-energy electron fluxes is given by the responses of the magnetic spectrometer G.M. tubes, $\mathrm{SpL}$ and $\mathrm{SpH}$, and

5) the charged particle total energy fluxes, as measured with the CDSTE at $\mathrm{L}=3.5$, were a factor of $\sim 2$ larger for the period $2-14$ October after the main phase of the storm when compared to the pre-storm measurements of $21-30$ september over the geomagnetic latitude range $25^{\circ} \leq \lambda_{\mathrm{m}} \leq 45^{\circ}$.

No mechanism for providing these large energy fluxes of electrons $100 \mathrm{eV} \leq \mathrm{E}_{\mathrm{e}} \leq 40 \mathrm{keV}$ is proposed here due to lack of energy spectra, angular distributions, and sensitivity for definitive measurements at higher L-values, i.e., I > 4. It is clear that a slow diffusion across L-shells as suggested for $\sim 1 \mathrm{MeV}$ electrons [cf. Frank, 1965] is inadequate, without fundamental modification, to account for the rapid enhancement (within 1 day or less of the onset of the geomagnetic storm) deep in the earth's magnetosphere at $L \sim 3.0$ since the increase 
of electron $\mathrm{E}_{e} \sim 1 \mathrm{MeV}$ intensities at $\mathrm{L} \simeq 3.5$ is observed to occur after a period $\sim 1$ week following the onset of a magnetic storm. The observational evidence strongly suggests an acceleration mechanism for electrons $E_{e} \sim$ 1 - $100 \mathrm{keV}$ which is active deep in the earth's magnetosphere, $I \gtrsim 2.8$.

It is of interest to estimate the perturbation in the horizontal component of the earth's magnetic field as seen by a magnetic observatory at the surface of the earth near the magnetic equator which is produced by the enhanced electron energy fluxes as reported here during the main phase of a geomagnetic storm. An estimate of the decrease in the magnetic field intensity, $\Delta B$, at the magnetic equator on the earth's surface due to these low-energy electrons is given by $\Delta B=k\left(W_{e} / W_{B}\right) B_{0}$ where $\Delta B$ is in units of gauss if $B_{0}=0.31, W_{e}$ is the total energy in ergs of these electrons in the geomagnetic field, $W_{B}$ is the total energy of the geomagnetic field $\left(8.4 \times 10^{24} \mathrm{ergs}\right)$ and $k$ is a dimensionless factor of the order of unity [ cf Parker, 1965]. The total energy $W_{e}$ of the low-energy electrons reported here is estimated by assuming an energy flux of 1000 ergs $\left(\mathrm{cm}^{2}-\mathrm{sec}\right)^{-1}$ over a volume contained by the surfaces $L=2.8$ and 4.0 between geomagnetic latitudes $\lambda_{\mathrm{m}}=+35^{\circ}$ and $-35^{\circ}\left(2 \times 10^{28} \mathrm{~cm}^{3}\right)$; the resulting estimate is 
Table V

Estimates of The Magnetic Field Perturbation, $\Delta \mathrm{B}$, Seen At The Earth's Surface For An Electron Energy Flux 1000 Ergs $\left(\mathrm{Cm}^{2}-\mathrm{Sec}\right)^{-1}$ Distributed Over

$L=2.8$ to $4.0, \lambda_{\mathrm{m}}=-35^{\circ}$ to $+35^{\circ}$

\begin{tabular}{|c|c|c|}
\hline $\begin{array}{c}\text { Electron } \\
\text { Energy Ee,keV }\end{array}$ & $\begin{array}{c}\text { Total Electron } \\
\text { Energy } \mathrm{We}_{\mathrm{e}} \text { ergs }\end{array}$ & $\Delta \mathrm{B}$, gammas \\
\hline 0.1 & $3.4 \times 10^{22}$ & $120^{*}$ \\
0.2 & $2.4 \times 10^{22}$ & $88^{*}$ \\
0.5 & $1.6 \times 10^{22}$ & 58 \\
\hline 1 & $1.1 \times 10^{22}$ & 39 \\
2 & $7.6 \times 10^{21}$ & 28 \\
5 & $4.8 \times 10^{21}$ & 18 \\
\hline 10 & $3.4 \times 10^{21}$ & 12 \\
20 & $2.4 \times 10^{21}$ & 9 \\
50 & $1.6 \times 10^{21}$ & 6 \\
\hline
\end{tabular}

$*_{B}>0.3$ at $\mathrm{L}=3.5, \mathrm{~B} / \mathrm{B}_{\mathrm{O}}=1$ in this approximation. 
judged to be accurate to within a factor of 3 for the

1 October 1961 observations. In Table $\mathrm{V}$ are summarized

the estimates of $\Delta B$ for monoenergetic electrons with energy $E_{e}$ corresponding to an energy flux of $1000 \mathrm{ergs}\left(\mathrm{cm}^{2}-\mathrm{sec}\right)^{-1}$ throughout the above volume. For electron energies $E_{e}=0.2$, 1 and $5 \mathrm{keV}$, the decrease in field intensity, $\Delta \mathrm{B}$, is 90,40 and $20 \gamma$, respectively. The $\mathrm{D}_{\text {st }}(\mathrm{H})$ values for 1 October were $\sim-150 \gamma\left(I \gamma=10^{-5}\right.$ gauss). Hence, although the present experiment is unable to provide the energy spectra of electrons $100 \mathrm{eV} \leqslant \mathrm{E}_{e} \approx 40 \mathrm{keV}$, the above estimates of the total energy of the observed electron energy fluxes, the correlation of the large enhancements of these electron energy fluxes with the main phases of two magnetic storms (see Figures 1 and 2) and the rapid decay ( $\lesssim 24$ hours) of both phenomena strongly suggest that these electrons form a ring current centered at $\sim 3 R_{E}$ wich is responsible for a substantial fraction of the main phase and the rapid-decay component (designated as the DRI component by Akasofu, Chapman and Venkatesan [1963]) of magnetic storms. It is further noted here that the CDSB upper limit on the proton $E_{p} \gtrsim 400 \mathrm{keV}$ energy fluxes is $\sim 100$ ergs $\left(\mathrm{cm}^{2}-\mathrm{sec}\right)^{-1}$ at $I \sim 3$ during the main phases of these two magnetic storms, an upper limit which is not low enough to eliminate a low-energy proton ring current of similar or greater magnitude when compared with the above low-energy electron ring current. 


\section{Acknowledgements}

The author is indebted to J. A. Van Allen for several stimulating discussions concerning this investigation. J. Freeman and C. Laughlin were responsible for the design, fabrication, and calibration of the cadmium sulfide detectors and the magnetic spectrometer, respectively. The efforts of F. McDonald, L. Davis, and P. Butler of the Goddard Space Flight Center toward the successful completion of the Explorer 12 project are gratefully acknowledged. This research was supported in part by the National Aeronautics and Space Administration under Grant NsG-233-62 and by the Office of Naval Research under Contract Nonr-1509(06). 


\section{References}

Akasofu, S.-I., S. Chapman, and D. Venkatesan, The main phase of great magnetic storms, J. Geophys. Res., 68, $3345-3350,1963$.

Dessler, A. J., and E. H. Vestine, Maximum total energy of the Van Allen radiation belt, J. Geophys. Res., 65, 1069-1071, 1960.

Frank, L. A., Efficiency of a Geiger-Mueller tube for nonpenetrating electrons, J. Franklin Inst., 273, 91-106, 1962 .

Frank, L. A., Inward radial diffusion of electrons of greater than 1.6 million electron volts in the outer radiation zone, J. Geophys. Res., 70, 3533-3540, 1965.

Frank, L. A., J. A. Van Allen, W. A. Whelpley, and J. D. Craven, Absolute intensities of geomagnetically trapped particles with Explorer 14, J. Geophys. Res., 68, 1573-1579, 1963.

Frank, L. A., J. A. Van Allen, and H. K. Hills, A study of charged particles in the earth's outer radiation zone with Explorer 14, J. Geophys. Res., 69, 2171-2191, 1964.

Freeman, J. W., A satellite borne cadmium sulfide total corpuscular energy detector, State University of Iowa Research Report, 61-2, February 1961, (unpublished). 
Freeman, J. W., The morphology of the electron distribution in the outer radiation zone and near the magnetospheric boundary as observed by Explorer XII, J. Geophys. Res., 69, $1691-1723,1964$.

Parker, E. N., Paper presented at the Advanced Study Institute on Radiation Trapped in the Earth's Magnetic Field, Bergen, Norway, 16 August 1965 (to be published in Proceedings, 1966).

Van Allen, J. A., Some general aspects of the geomagnetically trapped radiation, Proceedings of the Advanced Study Institute on Radiation Trapped in the Earth's Magnetic Field, Bergen, Norway, 16 August 1965 (to be published, 1966) 


\section{Figure Captions}

Figure 1. The responses of CDSTE, CDSB and CDSO for the period 21 September through 14 October 1961 for $L=2.5,3.0,3.5$, and 4.0. The range in geomagnetic latitude $\left|\lambda_{\mathrm{m}}\right|$ is $20^{\circ}$ to $45^{\circ}$. The daily mean variation of the horizontal intensity measured at Guam is included for comparison.

Figure 2. A continuation of Figure 1 for $L=3.5$ and the period 21 October through 13 November.

Figure 3. Latitude dependence of CDSTE responses for $L=3.5$ of Figure 1 separated into the periods of pre-storm, first day of storm (1 October), and post-1 october data.

Figure 4. Responses of the spectrometer channels SpI and $\mathrm{SpH}$ and the 302 G.M. tube at $\mathrm{L}=3.5$ compared with the responses of CDSTE for the period 21 September through 14 October 1961 (refer to Figure 1).

Figure 5. Comparison of the profiles of 302 G.M. tube and the CDSTE responses as a function of $L$ for two similar outbound passes of Explorer 12 on 30 September and I October 1961. Geomagnetic latitudes for these passes have been included for several values of $L$. 


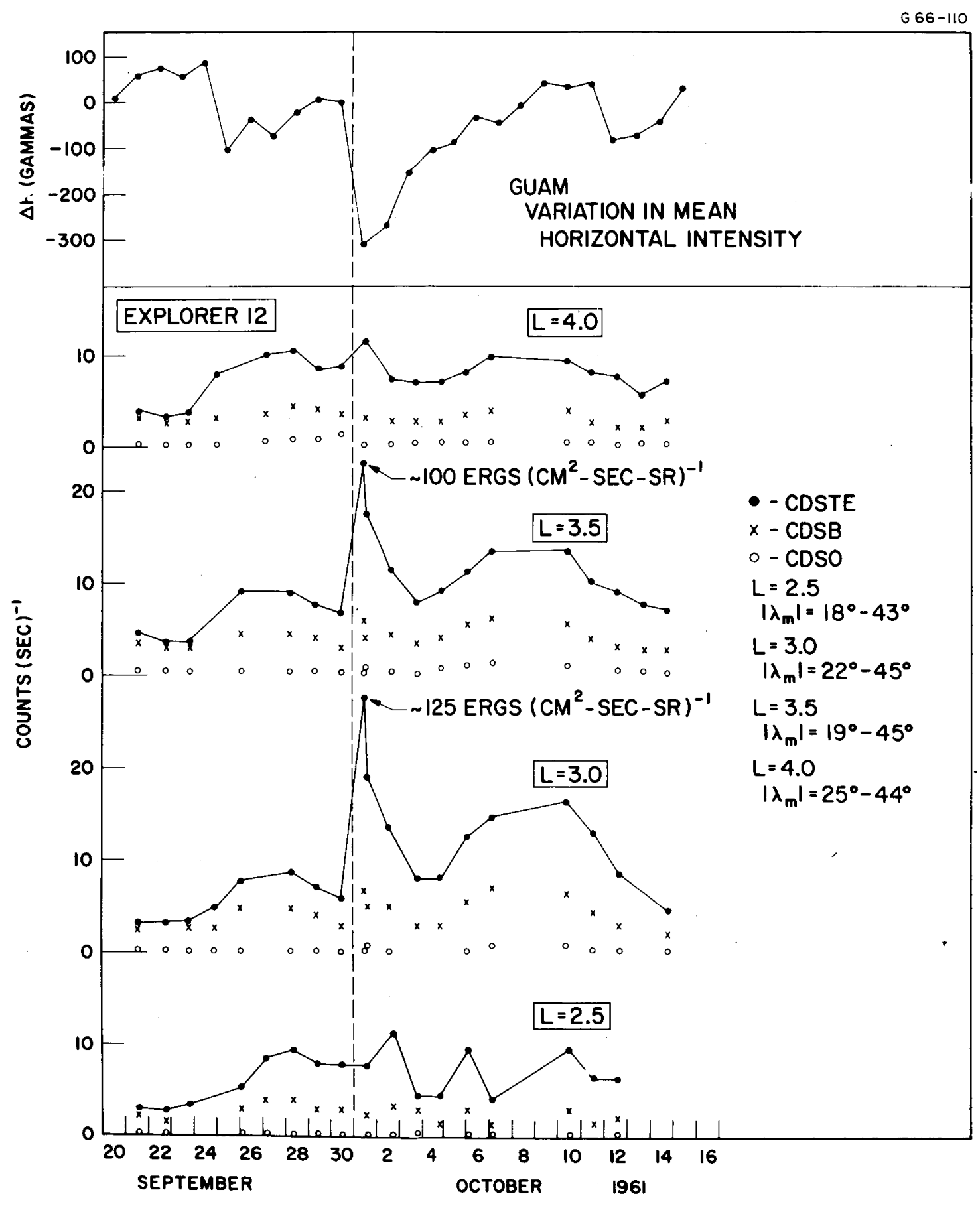

Figure 1 


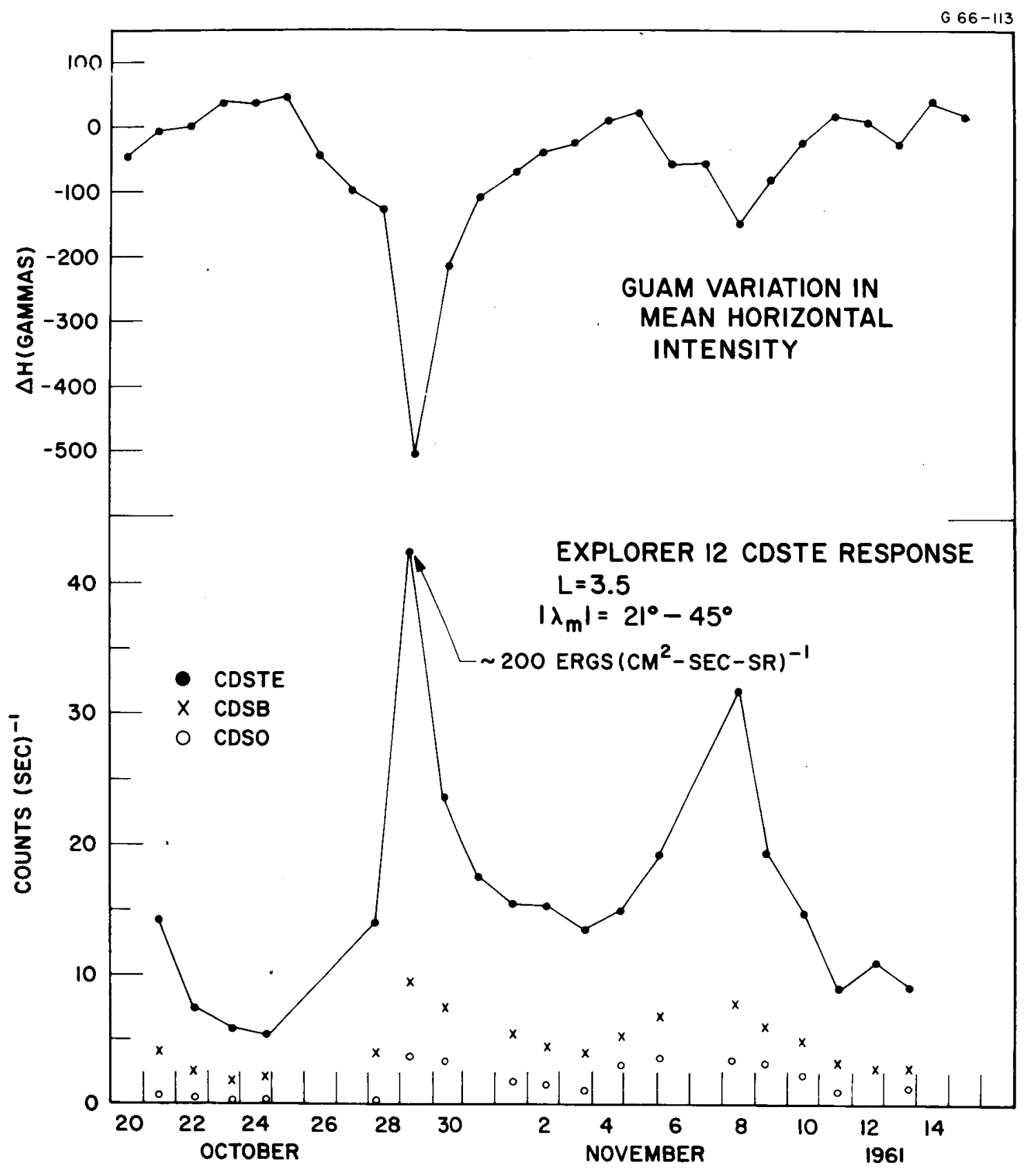

Figure 2 


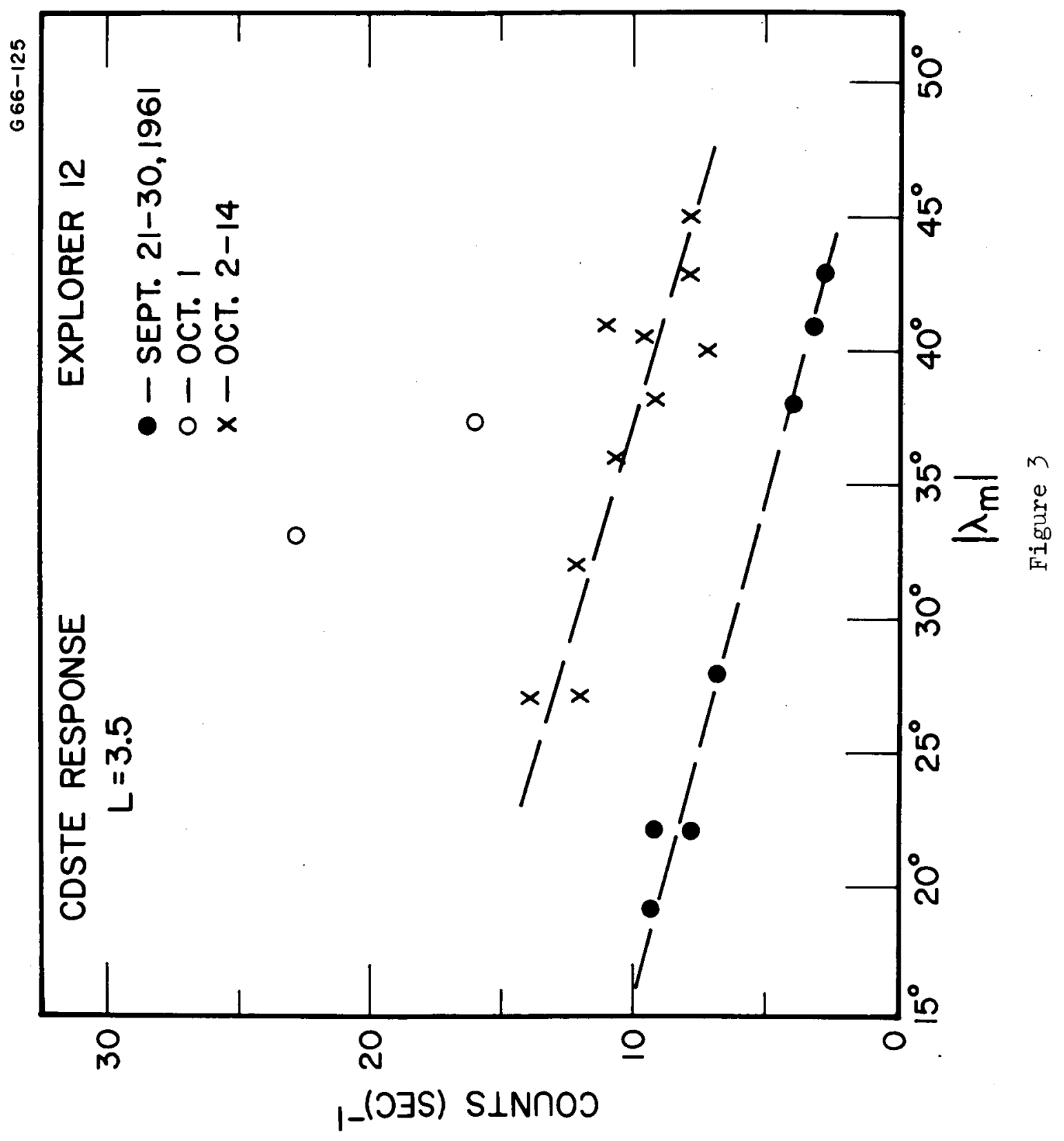




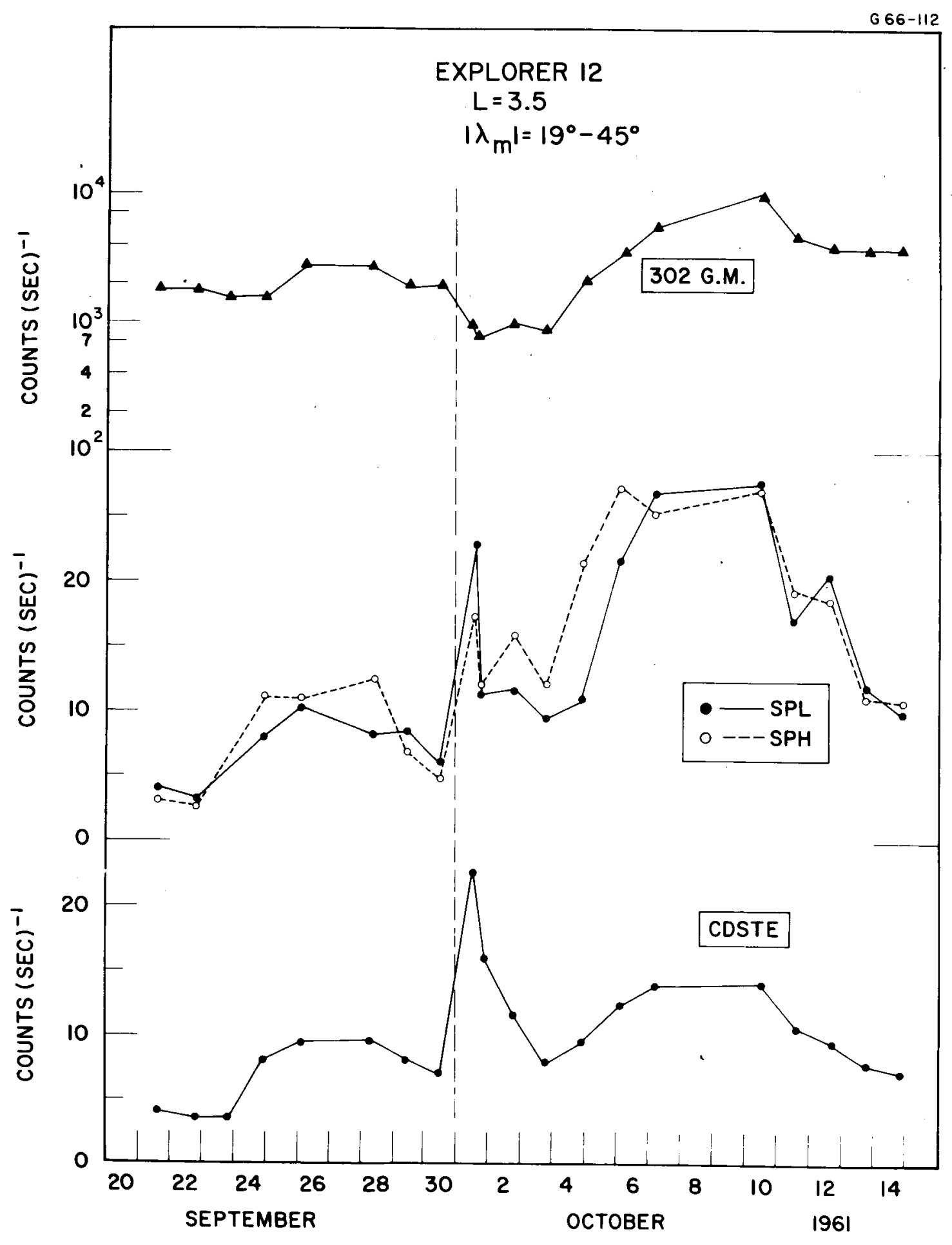

Figure 4 


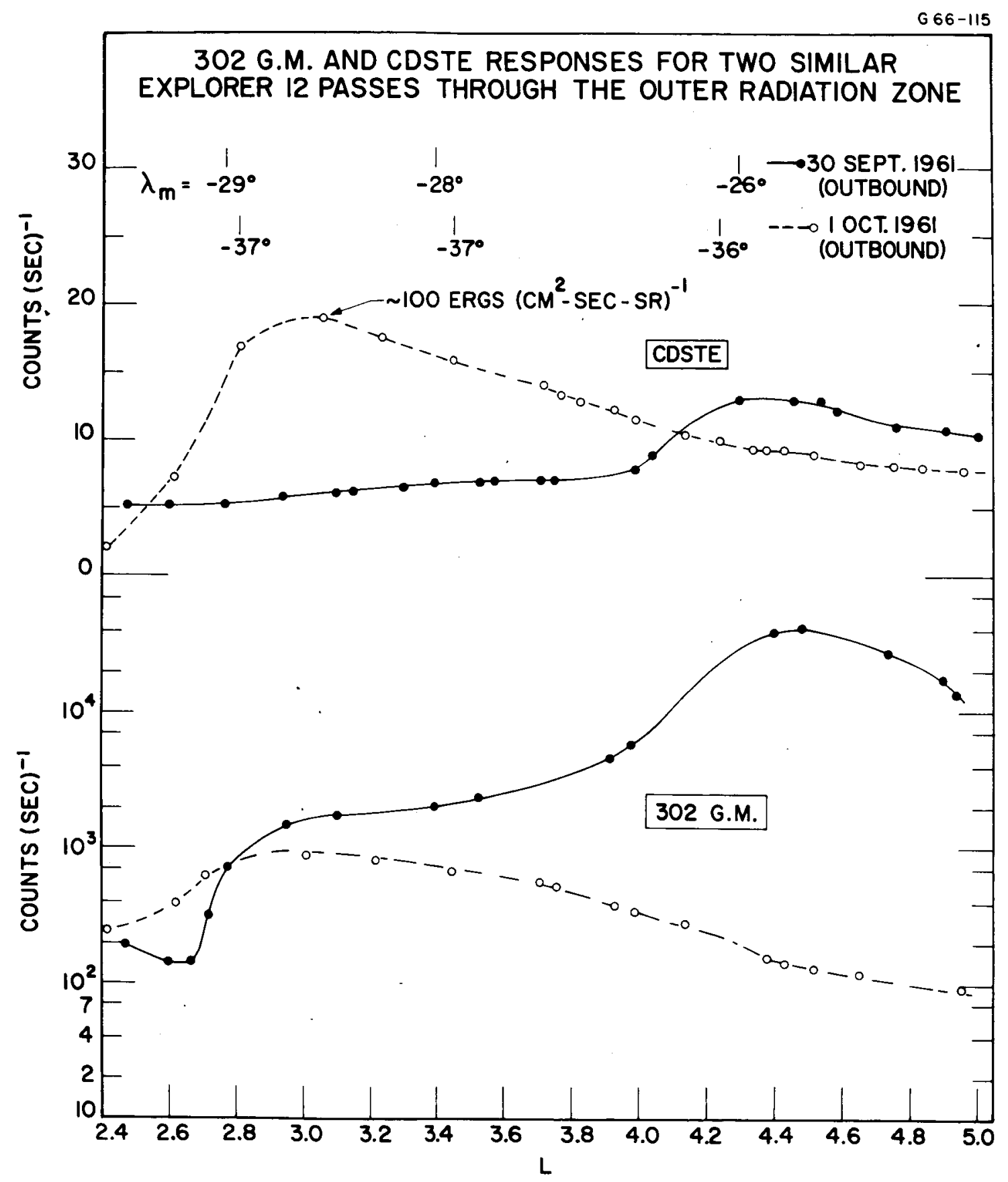

Figure 5 


\section{DOCUNIENT CONTROL DATA - R\&D}

(Secufiv cinssification of title. bodv of abstenct and infexinf annotation must be entered when the ovorall report is classitied)

OnIGINATING ACTIVITY (Corporatc author)
University of Iowa, Department of Physics and
Astronomy

3 REPORT TITLE

Explorer 12 Observations of The Temporal Variations of Low-Energy Electron Intensities In The Outer Radiation Zone During Geomagnetic Storms

4. OESCRIPTIVE NOTES (Type of roport and inclusive dates)

Progress

5. AUTHOR(S) (Last namo, firs i name, initial)

Frank, I. A.

\begin{tabular}{|c|c|c|}
\hline $\begin{array}{l}\text { DEPORT OATE } \\
\text { March } 1966\end{array}$ & $\begin{array}{l}\text { 7a. TOTAL NO OF PAGES } \\
36\end{array}$ & $\begin{array}{c}\text { 7b. NO. OF REFS } \\
10\end{array}$ \\
\hline $\begin{array}{l}\text { Ba. CONTRACT OR GRANT NO. NONR-1509(06) } \\
\text { b. PROJECT NO. }\end{array}$ & $\begin{array}{l}\text { 9a. ORIGINATOR'S REPORT } \\
\text { U. Of IOWa } 66-8\end{array}$ & $B E R(S)$ \\
\hline c. & $\begin{array}{l}\text { 9b. OTHERREPORT NO(S) } \\
\text { (his repOrt) }\end{array}$ & other numbors that $n$ \\
\hline
\end{tabular}

1O. AVAILABILITY/LIMITATION NOTICES

Qualified requesters may obtain copies of this report from DDC.

11. SUPPLEMENTARY NOTES

12. SPONSORING MILITARY ACTIVITY

Office of Naval Research

13. ABSTRACT

Large increases of electron $100 \mathrm{eV} \lesssim \mathrm{E} \lesssim 40 \mathrm{keV}$ energy fluxes over $\mathrm{L} \simeq 2.8$ to $\mathrm{L} \simeq 4.0$ were observed at the onset of magnetic storms on 1 October an $\bar{d} 29$ October 1961 with instrumentation on Explorer 12 . The omnidirectional energy fluxes at $\mathrm{L}=3.5$ were $\sim 1000$ ergs $\left(\mathrm{cm}^{2}-\mathrm{sec}\right)^{-1}$ for these two events, the duration of these events was approximately one day and the peak energy flux was positioned at $L \sim 3.0$. The large enhancement of electron $100 \mathrm{eV} \approx \mathrm{E} \lesssim 40 \mathrm{keV}$ energy fluxes on 1 October is coincident with large decreases of electron $\mathrm{E} \gtrsim 1.6 \mathrm{MeV}$.intensities and with increases of electron $40 \mathrm{keV}<\mathrm{E} \leq 10 \tilde{O} \mathrm{keV}$ intensities in the outer radiation zone. Although no spectral information concerning the electron $100 \mathrm{eV} \leqslant \mathrm{E} \lesssim 40 \mathrm{keV}$ fluxes is available, estimates of the decrease of the magnetic field on the surface of the earth at the magnetic equator for monoenergetic electron intensities corresponding to the observed energy fluxes are $\sim 120 \gamma$ for $\mathrm{E}_{\mathrm{e}}=100 \mathrm{eV}, \sim 60 \gamma$ for $\mathrm{E}_{\mathrm{e}}=500 \mathrm{eV}$ and $\sim 30 \gamma$ for $\mathrm{E}_{\mathrm{e}}=2 \mathrm{keV}$ during the main phase of the magnetic storm. The observations reported here strongly suggest that these electrons form a ring current centered at $\sim 3 \mathrm{R}_{\mathrm{F}}$ which is responsible for a substantial fraction of the main phase and the rapiddecay component DRI of magnetic storms. 


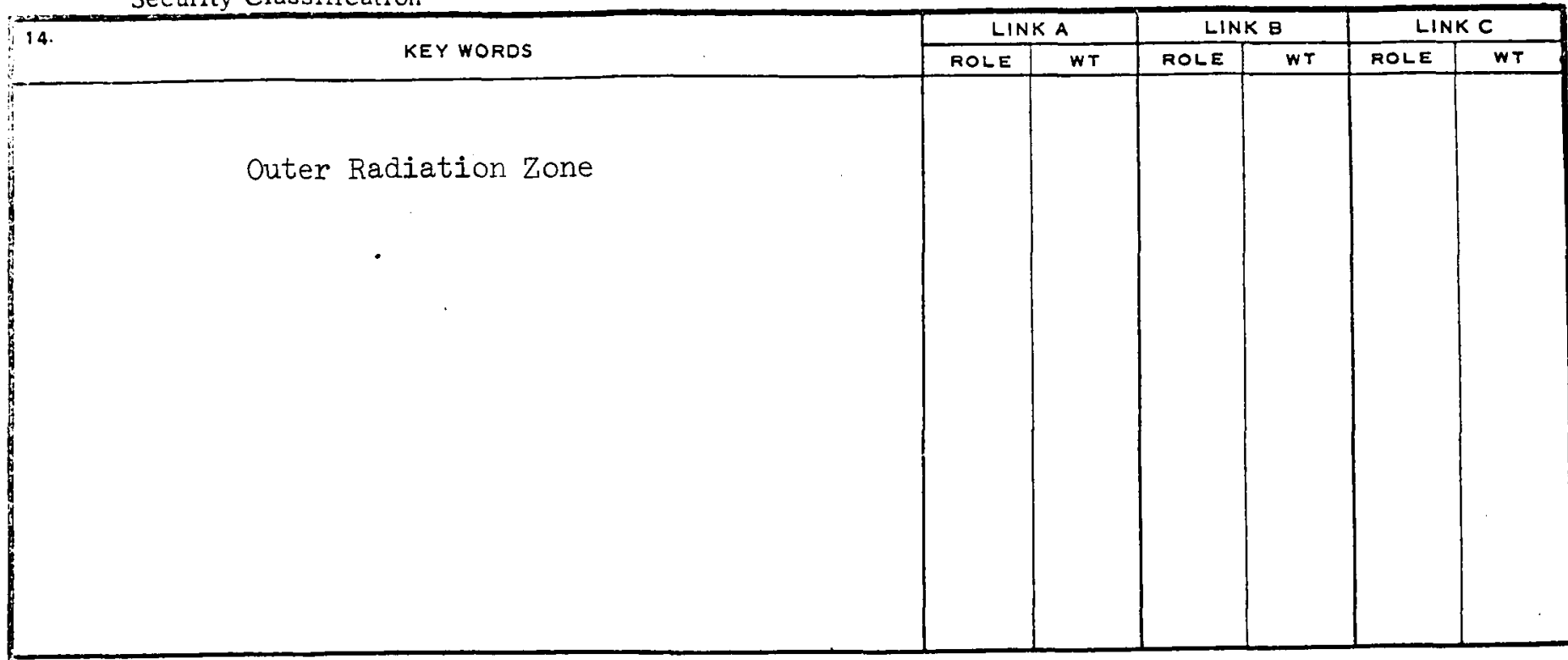

\section{INSTRUCTIONS}

1. ORIGINATING ACTIVITY: Enter the name and address of the contractor, subcontractor, grantee, Department of Defense activity or other organization (comorate author) issuing the report.

2a. REPORT SECURTY CLASSIFICATION: Enter the overall security classification of the report. Indicate whether "Restricted Data" is included. Marking is to be in accordance with appropriate security regulations.

2b. GROUP: Automatic downgrading is specified in DoD Directive 5200.10 and Armed Forces Industrial Manual. Enter the group number. Also, when applicable, show that optional markings have been us ed for Group 3 and Group 4 as authorized.

3. REPORT TITLE: Enter the complete report title in all capital letters. Titles in all cases should be unclassified. If a meaningful title cannot be selected without classification, show title classification in all capitals in parenthesis immediately following the title.

4. DESCRIPTIVE NOTES: If appropriate, enter the type of report, e.g., interim, progress, summary, annual, or final. Give the inclusive dates when a specific reporting period is covered.

5. AUTHOR(S): Enter the name(s) of author(s) as shown on or in the report. Enter last name, first name, middle initial. If rilitary, show rank and branch of service. The name of the principal ditthor is an absolute minimum requirement.

6. REPORT DATE: Enter the date of the report as day, month, year; or month, year. If more than one date appears on the report, use date of publication.

7a. TOTAL NUMBER OF PAGES: The total page count should follow normal pagination procedures, $i . e$. , enter the number of pages containing information

7b. NUMBER OF REFERENCES. Enter the total number of references cited in the report.

8a. CONTRACT OR GRANT NUMBER: If appropriate, enter the applicable number of the contract or grant under which the report was written.

$8 b, \& c, \& 8 d$. PROJECT NUMBER: Enter the appropriate military department identific ation, such as project number, subproject number, system numbers, task number, etc.

9a. ORIGINATOR'S REPORT NUMBER(S): Enter the official report number by which the document will be ident ified and controlled by the originating activity. This number must be unique to this report.

Gb. OTHER REPORT NUMBER(S): If the report has been assigned any other report numbers (either by the originator or by the sponsor), al so enter this number(s).

10. AVAIL ABILITY/LIMITATION NOTICES: Enter any limitations on further dissemination of the report, other than those imposed by security classification, using standard statements such as:

(1) "Qualified requesters may obtain copies of this report from DDC"

(2) "Foreign announcement and dissemination of this report by DDC is not authorized."

(3) "U. S. Government agencies may obtain copies of this report directly from DDC. Other qualified DDC users shall request through

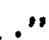

(4) "U. S. military agencies may obtain copies of this report directly from DDC. Other qualified users shall request through

(5) "All distribution of this report is controlled Qualified DDC users shall request through .1

If the report has been furnished to the Office of Technical Services, Department of Commerce, for sale to the public, indicate this fact and enter the price, if known.

11. SUPPLEMENTARY NOTES: Use for additional explanatory notes.

12. SPONSORING MILITARY ACTIVITY: Enter the name of the departmental project office or laboratory sponsoring (pay ing (or) the research and development. Include address.

13. ABSTRACT: Enter an abstract giving a brief and factual summary of the document indicative of the report, even though it may also appear elsewhere in the body of the technical report. If additional space is required, a continuation sheet shall be attached.

It is highly desirable that the abstract of classified reports be unclassified. Each paragraph of the abstract shall end with an indication of the military security classification of the information in the paragraph, represented as $(T S),(S),(C)$, or $(U)$.

There is no limitation on the length of the abstract. However, the suggested length is from 150 to 225 words.

14. KEY WORDS: Key words are technically meaningful terms or short phrases that characterize a report and may be used as index entries for cataloging the report. Key words must be selected so that no security classification is required. Identifiers, such as equipment model designation, trade name, military project code name, geographic location, may be used as key words but will be followed by an indication of technical context. The assignment of links, rales, and weights is optional. 